\title{
Semblante, discurso y simulacro en la escena contemporánea
}

\section{Semblance, Discourse and Simulacrum in the contemporary scene}

Mandela Indiana Muniagurria Universidad de Buenos Aires, Facultad de Ciencias Sociales, IIGG/CONICET mandelaindiana@icloud.com

Miguel Ángel Rossi CONICET, IESYP de PAT/ Universidad de Buenos Aires, Facultad de Ciencias Sociales mrossi@lorien-sistemas.com

Resumen: El presente trabajo tematiza la centralidad de la imagen en la contemporaneidad, atendiendo a la problemática del lazo social desde el psicoanálisis lacaniano. En este sentido, a partir del anudamiento borromeano entre los registros real, simbólico e imaginario, se interroga acerca de la distinción entre semblante y simulacro, así como también sobre las implicancias que para el lazo social tiene la apelación a una idea de pura imagen desembarazada de inscripción discursiva.

Palabras clave: semblante, simulacro, psicoanálisis, imagen, discurso.

Abstract: The present work thematizes the centrality of the image in contemporaneity, attending to the problem of the social bond from a Lacanian perspective. Parting from the Borromean knot between the 
real, symbolic and imaginary registers, the article will tackle the distinction between semblance and simulacrum, as well as the effects that the idea of a pure image without discursive inscription may have for the social bond.

Keywords: Semblance, Simulacrum, Psychoanalysis, Image, Discourse.

Recibido: I4 de noviembre de 2020

Aceptado: 30 de diciembre de 2020 https://dx.doi.org/IO.I 5 I 74/rv.vi 3i27.586

\section{I}

Z $\mathrm{n}$ su repetición inmediata o metaforizada, en sus efectos y en Esu discursividad, hay un concepto que tiene en la contemporaneidad una evidente relevancia. El concepto es el de imagen. Redes sociales en las que la escritura está casi ausente, publicidad, estética, culto a la belleza. Tanto en su apelación constante, como en las críticas de su predominio, la imagen constituye la forma predilecta del decir contemporáneo, la forma más frecuente de la presentación de sí y de la evocación al otro (Bassols, 2017; Leserre, 2018; Miller, 2009). Señalar su centralidad no equivale a indicar el peso del significante "imagen”, que seguramente lo tenga. Más bien, se trata de demarcar su primacía en tanto modo de aprehender, pensar, idear y hasta de ser en el mundo.

Además de su significación más cotidiana, vinculada a lo figurativo, la imagen evoca una serie de nociones muy oídas en los campos de las ciencias sociales y las humanidades: imaginario, imaginación, imaginarización. Términos que indican, con sus torsiones y desacoples, que la instancia de la imagen y de lo imaginario tienen un rol ineludible en la constitución del lazo social, de la 
vida en común, del ser con otros. ${ }^{1}$ Para el psicoanálisis lacaniano, la imagen es fundamental en la formación del yo, ${ }^{2}$ en la medida en que se figura como la representación alienada, totalizada y totalizante al mismo tiempo; unificante y cerrada, siempre amenazada con la ruptura, con el resquebrajamiento o la disgregación. No es un mero reflejo o copia (distorsionada o literal) del objeto que representa, sino ese lugar que le ofrece al sujeto una figuración sin fallas, discontinuidades o agujeros. Por eso, formulaciones tales como "yo", "comunidad", "cuerpo" o "nación", en tanto instancias de unidad o incluso de homogeneidad, pueden pensarse como apelaciones imaginarias.

La imagen es poderosa y atrapante, ya que no supone la mortificación propia del registro simbólico, la castración: el significante representa algo ausente, implicando pérdida, tachadura, falta de significado último. Sin embargo (y por ello mismo), el reverso de una totalidad imaginada suele ser devastador: una realidad despedazada o desagregada. En todo caso, se trataría de una homogeneidad fuerte y lábil al mismo tiempo, amenazada constantemente por su ruptura. Lejos de ser constituida por el yo, la imagen es constituyente de aquél, lo cual revela un plano activo de lo imagi-

${ }^{1}$ Existen múltiples desarrollos en las ciencias sociales acerca de la instancia de la imagen para la conformación del campo social, tales como los verificados en la obra de Cornelius Castoriadis (1993), Merleau-Ponty (2010), Sartre (2005; 2006), entre otros. Hacemos esta mención con el fin de ubicar la pertinencia del abordaje psicoanalítico sobre este punto.

${ }^{2}$ Aquí debemos distinguir al "yo" imaginario del sujeto en cuanto este último emerge como efecto del lenguaje en la medida en que toma, para representarse parcialmente, un rasgo del gran Otro entendido como el lugar o garantía del registro simbólico. Esta relación de alienación y separación al significante -que es distinta de la alienación a la imagen-, se inscribe en el terreno de la falta, de la castración y la división subjetiva por la cual hablamos y somos hablados por otros. Sobre la identificación simbólica al rasgo unario en tanto transporte de la diferencia (vid. Lacan, 2009). 
nario en la conformación del cuerpo, y desanda al mismo tiempo una tradición en la cual la imagen es un mero reflejo de las cosas.

En este sentido, la novedad del fenómeno en cuestión estaría, no tanto en la apelación a la imagen -eso, como señalábamos más arriba, es constitutivo de todo ordenamiento, estructura o identidad-, sino más bien en una imaginarización de lo real (Mankoff, 2018: 23), para decirlo con la distinción de los registros lacanianos sobre los que volveremos más adelante. En otras palabras, se indica una pretensión de atrapar en la imagen aquello que es inasimilable o, más aún, una presentación de la imagen como lo real mismo; la construcción de una hiperrealidad. Como veremos en nuestro trabajo, se trata de una torsión que declara la muerte de los semblantes en su intento de atrapar lo real, tal como si pudiese existir una realidad sin semblante. Aquí cabría una diferenciación importante entre lo real, en sentido lacaniano, y la realidad, que siempre es una construcción simbólico-imaginaria. De allí que el semblante no se opone a la verdad o falsedad, sino a lo real lacaniano, aquello que escapa a ser apresado por la significación.

Asumiendo que el psicoanálisis es un modo de lectura que, dirigiéndose hacia aquello que no cuadra, habilita un pensamiento sobre los bordes o agujeros de todo discurso que se pretenda totalizante, el presente trabajo busca elaborar un análisis crítico de la primacía de la imagen en la contemporaneidad. Por ello, los interrogantes que aquí ensayaremos partirán de la noción lacaniana de semblante, como figura simbólica con investidura imaginaria, y su distinción del simulacro. Se tratará de indicar las apoyaturas simbólicas e imaginarias que, respectivamente, tienen cada una de esas categorías, con el objeto de pensar las implicancias y los reversos de la imaginarización, así como también de indicar el rol de sostén que cumple el orden significante en toda figuración imaginaria. Estos reversos serán leídos especialmente a la luz del anudamiento predominante entre imaginario y real en la contemporaneidad, 
desde el que, por una parte, el otro deviene siempre una amenaza y, por otra, se da un "empuje a la literalidad" (Bermúdez et. al., 2018: 116), evidenciado en las múltiples transformaciones del cuerpo que posibilitan las tecnociencias.

En un primer apartado, nos abocaremos a introducir sucintamente los registros imaginario y simbólico, haciendo especial énfasis en las consideraciones del ultimísimo Lacan (Miller, 2014) acerca del necesario anudamiento de los tres órdenes y su imposibilidad de pensarlos separadamente, implicando a veces una mayor o menor preponderancia de algunos de sus anudamientos específicos. Más adelante, nos ocuparemos de la categoría de semblante, desarrollada por el psicoanalista francés fundamentalmente en su Seminario 18, intitulado De un discurso que no fuera del semblante, pero marcando su ligazón con el orden discursivo, objeto de su seminario anterior, El reverso del psicoanálisis. Distinguiremos la operación del semblante de un simple enmascaramiento para señalar su dimensión capital en tanto inscripción en un orden simbólico, tal como se piensa en relación con los procesos de sexuación. Hacia el final, ensayaremos una lectura del simulacro como paradigma de la imaginarización de lo real, atendiendo a la proliferación de identidades sexuales y la primacía de la autopercepción. Sin obturar este último nivel, que es constitutivo y fundamental para la subjetividad, formularemos una serie de interrogantes acerca de las implicancias que algunas de sus modulaciones conllevan para la constitución del lazo social, así como también para la formulación de sujetos colectivos. Interrogarse, en otras palabras, si una imagen porta por sí sola significación o si, por otra parte, es sobre y a partir de un encadenamiento significante que se posibilita la inscripción en un orden simbólico, la articulación de un lazo con otros y otras, la constitución de identidades menos homogéneas, pero no por eso amenazadas por el riesgo de su disgregación. 
Si partimos del nudo borromeo -al que Lacan recién apela a partir de su Seminario 19 ... O peor- para introducir los tres registros es porque, entre otras razones, este permite dar cuenta de su articulación simultánea, y al mismo tiempo, irreductible. En otras palabras, porque muestra que ninguno de los tres órdenes tiene absoluta autonomía respecto de los otros, sino que deben ser pensados en su anudamiento, tal como se observa en la figura:

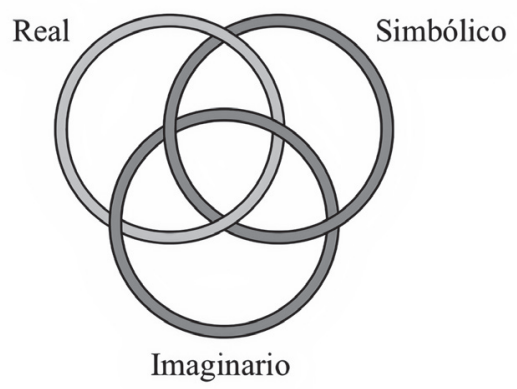

En su estructuración, el nudo es indicativo de lo necesario de su atadura ya que, tal como señala Lacan (2012), si uno de los cordeles se cortara el conjunto entero se dispersaría. Al mismo tiempo, es posible observar que ningún orden prevalece sobre el resto, sino que la articulación es triple, de mutua implicación (Miller, 1999). Ello no supone que sean homogéneos, que no comporten una particularidad específica e irreductible, como ya anticipamos, pero sí que están necesariamente articulados: es imposible abordar cualquiera de los círculos sin advertir que se encuentran conectados 
entre sí. ${ }^{3}$ Sin embargo, es preciso señalar que esta demarcación doble de la co-constitución y de la irreductibilidad no siempre estuvo acentuada del mismo modo, sino que se trata de una elaboración que aparece en sus últimos trabajos. En efecto, y como señala Miller (2004), es posible encontrar distintos momentos a lo largo de su trayectoria, donde se observa un acento distinto sobre cada uno de los registros, con efectos notables en las concepciones de goce, significante, objeto, o incluso en la dirección de la cura.

El nudo borromeo, en rigor, es una formalización de la (no) ontología. La negación no responde meramente a un criterio estilístico o poético, sino que evidencia que la experiencia está siempre atravesada por una hiancia o agujero, que no solo resiste a toda simbolización o representación imaginaria, incluso a su formulación bajo el "no hay" real, sino que se trata de un vacío irreductible e incolmable en el plano ontológico, en el que Lacan ubica al objeto $a$. Ahora bien, este elemento topológico permite acorralar ese vacío (Charaf, 2019), situarlo y funcionalizarlo: lo encierra y, al mismo tiempo, distribuye y administra los modos de operar de los registros en torno a él y entre sí, sus entrecruces y solapamientos. Para decirlo rápida y anticipadamente, el registro imaginario produce imágenes de totalidad que buscan taponar ese agujero disonante, el registro simbólico opera bajo el orden del significante que introduce la representación y la diferencia, y lo real pone de relieve, una y otra vez, la imposibilidad de esas operaciones, la persistencia del sinsentido o, en otras palabras, de la hiancia estructural (Miller, 2004). Es en virtud de esta estructuración que podemos abordar cada uno de los registros, como también la noción de semblante

\footnotetext{
${ }^{3}$ Como señala Roque Farrán, es necesario "acentuar la heterogeneidad de los registros contra cualquier tentación á la Hegel de totalización homogeneizante, por lo cual no hay unidad, reconciliación o síntesis dialéctica del conjunto; al contrario, hay tensiones debido a la irreductibilidadd y no dominio absoluto de uno sobre otro" (2009: 72).
} 
y su distinción del simulacro. Así, lo imaginario es pensado, por caso, como anticipábamos en la introducción, en tanto lugar de elaboración de imágenes - de completitud- que se sostienen sobre un entramado simbólico-discursivo que lo precede y lo constituye.

Lacan aborda este registro a partir del estadio del espejo, momento en el que se constituye el yo desde la identificación especular. Su escrito, El estadio del espejo como formador de la función del yo [je] tal como se nos revela en la experiencia psicoanalitica, cuestiona la configuración de la identificación en tanto alienación a un otro, partiendo de la escena en la que el bebé se ve reflejado en el espejo, así como también ante el ocultamiento y desocultamiento ante la mirada. Dos son los términos clave en este desarrollo: prematuración y anticipación. Ambos indican que en la constitución de la subjetividad, y desde el principio o incluso antes de ella, hay una falta. Esto implica sostener, a su vez, que mas que identidad hay identificación, es decir, que uno nunca es igual a sí mismo sino que siempre hay diferencia, más-que-uno. Veamos.

El bebé se encuentra en un estado de prematuración, por lo menos, en un doble sentido. Aunque bañado por el lenguaje -es decir, hablado y simbolizado por la cultura desde antes de su nacimiento- se encuentra en un momento pre-verbal, y en el que los signos que le vienen del otro le resultan enigmáticos y hasta intrusivos. Por otra parte, esta vulnerabilidad también es biológica, en tanto el cachorro humano no sobrevive sin el amor ni el cuidado material de otro, no puede valerse, ni alimentarse, ni sostenerse físicamente mas que a partir de otros que lo precedan. Tampoco tiene control ni noción de su cuerpo en tanto totalidad: este se percibe fragmentado, un juego de partes sin coordinación ni unidad.

En este sentido, la imagen que devuelve el reflejo especular en el otro tiene un rol fundacional, ya que es a partir de ella que el yo emerge en tanto tal. Ahora bien, esta identificación imaginaria funciona en cuanto es anticipatoria: la figura de su cuerpo que se 
refleja en el espejo -que por cierto es más ficticio que literal, ficción que viene de la presencia de otro- le permite al niño anticipar una completitud cerrada, acabada, tratándose de una antelación de la imagen por sobre lo motriz. En palabras de Lacan, esta imagen especular "asumida jubilosamente por el ser sumido todavía en la impotencia motriz y la dependencia de la lactancia (...) manifiesta, en una situación ejemplar, la matriz simbólica en la que el yo [je] se precipita en una forma primordial, antes de objetivarse en la dialéctica de la identificación con el otro y antes de que el lenguaje le restituya en lo universal su función de sujeto" (2003a: 87).

Esta figuración del cuerpo como imaginario echa por tierra cualquier interpretación que lo piense como natural. En efecto, pensar la "pura desnudez" resulta imposible: el cuerpo siempre está revestido de una imagen que permite "presentarnos y ocultar lo horroroso del cuerpo" (Baudes de Moresco, 2011: 34). Ese reverso despedazado del imaginario ilusorio puede ser ubicado en el cruce con lo real al que más arriba hacíamos mención, es decir, con lo real del cuerpo. Sin embargo, y como fue indicado, es el registro simbólico el que funciona como sostén de la identificación especular, ya que solo en la medida en que el Otro está presente en la escena -Otro simbólico, distinto del otro con minúscula, objeto de la alienación identificatoria- es que esta se posibilita. En efecto, hay un soporte simbólico porque la escena misma lo es: "espejo", "otro", "mirada", "palabra”, "yo", todos términos que cumplen un rol en la medida en que están investidos simbólicamente, ocupando un lugar en la cadena significante.

En cierto sentido, el orden simbólico es anterior al sujeto puesto que este es un efecto del lenguaje, entendido como un conjunto de normas, mandatos, disposiciones éticas, leyes culturales, etcétera. El sujeto en tanto tal emerge porque lo preexiste un entramado discursivo que lo aloja, lo nombra y lo soporta, y que al mismo tiempo le permite establecer lazos sociales. Pero indicar su carácter 
de "efecto" no implica pensarlo como mero producto de una operación simbólica de subjetivación, sino más bien como su falla, es decir que el sujeto es su producto fallido o no totalmente concretado. Este es producido por el orden simbólico representado bajo la figura del gran Otro, del cual toma un significante con el que se identifica. Pero tal como indica Lacan, si "un significante es lo que representa a un sujeto para otro significante" (2003c: 779), esto necesariamente implica que la representación siempre es parcial, siempre se da en el entre, nunca puede ser total. En este sentido, la introducción al orden del significante supone un costo, una libra de carne a pagar que tiene por efecto un sujeto dividido.

Lo que se establece en el seno del orden simbólico es una escisión, la imposibilidad de una relación estable entre un significante y un significado último, convirtiéndose el primero en un sustituto que intenta completar, siempre parcial y contingentemente, el vacío en la estructura. Dicho de otro modo, allí donde el gran Otro funciona como garante, como autoridad de la enunciación simbólica, también hay una barra, una falta, puesto que no hay ningún significante que escape al juego siempre metonímico de la significación, no hay metalenguaje, no hay Otro del Otro. Por ello mismo, cuando el sujeto pretende encontrar en el Otro la respuesta sobre su propia identidad, este no tiene respuestas para ofrecerle (Lacan, 2003).

Algunas de las implicancias políticas y sociales que podrían extraerse de estos supuestos, serían, principalmente, la imposibilidad de un fundamento último de lo social, tal como lo ha destacado el posfundacionalismo (Marchart, 2009), el carácter siempre abierto y contingente de las identidades sociales -que ha signado las discusiones del posmarxismo- (Laclau/Mouffe, 2006) y la imposibilidad de pensar la interpelación ideológica como operación cerrada y exclusivamente productiva (Zizek, 2003). El registro simbólico está estructurado alrededor de una imposibilidad, un "más allá 
[...] un núcleo real, un meollo traumático", un centro que es asimismo "un elemento extraño [...] que no puede ser simbolizado, integrado al orden" (Zizek, 2003: 177). En este sentido, lo real no es nouménico o presimbólico (en un sentido kantiano), como presuponen algunas lecturas (Butler, 2007), sino más bien aquello que solo se percibe a través de sus efectos simbólicos; a través de la inviabilidad de su inscripción pura con la que trastabilla toda representación. Inviabilidad que no es lo mismo que impotencia: es precisamente porque hay representación, que se habilita el infinito campo de las identificaciones imaginarias, las metáforas y metonimias, sin que haya un sentido prefijado de antemano.

En este sentido, lejos de implicar una prescindencia del orden imaginario, es a partir de la articulación de ambos registros -es decir, de lo simbólico y lo imaginario- que se habilita la sutura -parcial- del campo de representación, la fijación de identidades, el revestimiento de totalidad a las articulaciones simbólicas. Como veremos, en este entrecruzamiento se puede ubicar la categoría de semblante.

\section{III}

El anudamiento de los registros muestra que toda forma de la experiencia está siempre agujereada, incluso y sobre todo al nivel del ser. Lo real, en tanto imposible, descompleta las representaciones simbólicas o imaginarias, hace fracasar toda pretensión de pura representación. Al nivel del semblante, esto tiene muchas implicancias.

Desde la primera clase del Seminario 18, Lacan (2011) insiste en distinguir la noción de semblante del simple artificio o constructo, entendido como la exhibición de algo falso, opuesto a lo verdadero o auténtico. Este no es un mero aparentar en el sentido del engaño, sino que constituye el acto mismo de mostrarse, de 
darse a ver. No se define por algo más, no es semblante de otra cosa sino que vale, importa por sí mismo en la medida en que implica hacer semblante [faire semblant], presentarse e, incluso, ser ante otros.

Por ello mismo es que el semblante no es necesariamente algo "producido", o al menos no lo es en el sentido de lo engańoso de la producción o del constructo. Como indica Lacan al comienzo del seminario, el semblante es una elaboración necesaria para darse a ver o mostrarse ante la mirada, que desanda cualquier oposición entre falso y verdadero o, más aún, entre "artificio" y "naturaleza”. Es ese velo simbólico-imaginario no es un mero aparentar, sino el único modo bajo el que se puede presentar el ser hablante [parlêtre]. Que la verdad tenga "estructura de ficción" (Lacan, 2008: 176) implica, a riesgo de caer en la repetición, que no hay sino ficción. Sostener lo contrario implicaría suponer que detrás del velo del semblante habría efectivamente una Cosa a descubrir, a develar, pudiendo dar finalmente con "lo verdadero de lo verdadero" (Miller, 2009: 21). Sin embargo, eso no significa que no haya más allá -o más acá- de las representaciones -lo real es prueba de ello-, pero sí que ninguna de ellas puede ofrecer una metáfora que escape a esa imposibilidad.

Si semblante y verdad están anudados es precisamente porque no existe verdad sino echando mano a una estructura ficcional. Lo que no implica, al mismo tiempo, que verdad y semblante sean homologables, pero sí que puedan pensarse en una relación de ocultamiento. Si el semblante es el modo necesario y constitutivo del mostrar, una vez más, sostener que hay una verdad por fuera del orden del semblante, supondría creer en cierta instancia de "lo natural" limpio de lenguaje, de imagen, de metaforizaciones ${ }^{4}$. El

${ }^{4}$ Esta cuestión cobra especial relevancia en la actualidad, donde proliferan sintagmas y enunciaciones sobre "lo natural" como aquello contrapuesto a "lo 
punto es que allí donde se habla de naturaleza, como indica astutamente Lacan, también está operando una conjugación simbólicoimaginaria: arco iris, trueno, cortejo animal, meteoro, constelaciones; todas muestras que ofrece el psicoanalista francés para dar cuenta de que en ella los semblantes abundan. Es precisamente porque en la naturaleza no opera la estructura que resulta inviable pensarla como lo real, ya que este último solo "aparece como consecuencia de lo imposible" (Miller, 2009: 14). En suma, la naturaleza nunca es anterior a lo simbólico, no lo precede, nunca está desnuda, ni es posible aprehenderla en bruto, sino que es siempre ya ese "pizzarón" (Lacan, 2011: 48) en el que se han escrito significantes y leído sentidos.

Pero no solo en la naturaleza impera el semblante. Si atendemos el título del Seminario 18 -De un discurso que no fuera del semblante-, veremos que en él se incluye otro término a cuya articulación con el semblante Lacan se abocará en las primeras clases: discurso. En efecto, "estar en el semblante" no es un "hacer como si" o "pasar por" sino un modo de "regular el lazo social" (Bermúdez et. al., 2018: 116), es la condición de posibilidad de una inscripción simbólico-discursiva que determina toda posición subjetiva. El nombre del seminario, explica Lacan, es la formulación de una pregunta cuya respuesta está incluida en el interrogante mismo: la fórmula de la negación presupone la existencia de aquello que se niega por lo que, en rigor, el discurso sí es del orden del semblante $y$, un discurso que no fuera de ese orden, es decir, que atrapara

construido" o "alterado", por ejemplo, en los universos de la alimentación, los tratamientos médicos y sanitarios en general, la apariencia, la estética, etcétera. ${ }^{5}$ Como indica Miller, "que haya semblante en la naturaleza no implica que haya real. Realidad, toda la que se quiera, ipero no real!” (2009: 14). 
definitivamente lo real, que marcara un fundamento y garantía, como sabemos, es imposible. ${ }^{6}$

En este sentido, el semblante es el "objeto propio con el que se regula la economía del discurso" (Lacan, 2011: 18), el objeto que se produce en él, que lo administra y lo regula y que "tiene por efecto un sujeto" (Thompson, 2014: 572). Esto implica que el semblante -en tanto articulador del discurso- nunca es individual sino que es aquello que hace lazo social; lazo del que el sujeto en tanto tal, más que causa u origen, siempre es efecto. ${ }^{7}$ Entonces no solo es un modo del mostrarse, sino más bien el modo del mostrarse ante otros; modo de inscribirse en una trama significante. Las palabras inaugurales del seminario son bien indicativas de esta dimensión intersubjetiva: "De un discurso - no es el mío" (Lacan, 2011:9), anticipando lo que vendrá unas páginas más adelante, a saber, que un discurso no pertenece a un particular, sino que "se funda en una estructura" (2011: 10). ${ }^{8}$ Del mismo modo, así como no hay primero un sujeto y luego un discurso, tampoco hay hechos por fuera de este orden, ${ }^{9}$ cuestión que pone de relieve las consecuencias que el lenguaje tiene sobre la experiencia.

${ }^{6}$ "El juicio de atribución no prejuzga en nada la existencia, mientras que la sola posición de una Verneinung implica la existencia de algo que es precisamente lo que se niega. De un discurso que no fuera del semblante plantea que el discurso, como acabo de enunciarlo, es del semblante" (Lacan, 2011: 19).

${ }^{7}$ Como indicara Lacan en su inédita Conferencia de Milán del 12 de mayo de 1972: "El discurso ¿qué es? Es lo que, en el orden... en la disposición de lo que puede producirse por la existencia del lenguaje, tiene la función de lazo social" (Lacan, 1972).

${ }^{8}$ La fundación del discurso en una dimensión estructural no implica que el sujeto no sea, como seńalábamos al principio, su efecto real, es decir, la imposibilidad de la estructura de producirlo, subjetivarlo acabadamente.

9 "Solo que si a propósito hablé de artefacto, es porque para el discurso no hay nada de hecho, si puedo decirlo así, no hay ningún hecho más que por el hecho de decirlo. El hecho enunciado es a la vez el hecho de discurso. Esto es lo que 
Esta articulación con el discurso cobra especial relevancia en lo que respecta a la sexuación, ya que Lacan ubica al semblante en el seno mismo del "ser hombre" o "ser mujer". Distinta de toda biología u atribución cromosómica, la sexualidad es pensada a partir de la distribución binaria -y discursiva- de los sujetos en hombres y mujeres, desde la edad temprana, e incluso antes de su nacimiento. Si el semblante es "hacer creer que hay algo allí donde no hay" (Miller, 2009: 18), con las posiciones sexuadas sucede algo similar: se trata de un juego de ubicaciones que, lejos de tener significados unívocos, gira siempre en torno a un parecer que es siempre para otro u otra. ${ }^{10}$ En efecto, retomando la articulación entre semblante y naturaleza, Lacan recupera la idea de cortejo del mundo animal, pero indica que, a diferencia de este, la posición sexuada en tanto semblante en el universo de los seres hablantes se mediatiza en y a través del discurso.

Que el encuentro sexual esté mediado por el significante tiene implicancias, nuevamente, en múltiples niveles. Por un lado, supone que la sexualidad es una experiencia traumática para el sujeto que le impide asumir acabadamente una identidad sexual, por lo que nunca hay certidumbre plena sobre la misma (Zupančič, 2013; Copjec, 2006); el semblante no llega a decirlo todo del goce de cada quien, que es siempre singular y, por lo tanto, real. Al mismo tiempo, conlleva una incompletitud que se verifica en la ausencia de relación o acto sexual, es decir, de correspondencia o complementariedad entre los sexos. Por otro lado y en tanto mediación, la discursividad comporta la presencia de un tercero, el falo simbólico.

designo con el término artefacto y, por supuesto, es lo que se trata de poner en su lugar" (Lacan, 2011: 12).

10 "La identificación sexual no consiste en creerse hombre o mujer, sino en tener en cuenta que hay mujeres, para el muchacho, que hay hombres, para la muchacha" (Lacan, 2011: 33). 
Como significante, el falo administra el goce sexual y se distribuye de forma diferencial para las posiciones femenina y masculina. Tal como lo indica Lacan en La significación del falo, la "comedia" de los sexos supondrá relaciones específicas con este que "girarán alrededor de un ser y de un tener", que "tienen el efecto contrariado de dar por una parte realidad al sujeto en ese significante, y por otra parte irrealizar las relaciones que han de significarse" (2003b: 674). Un ser, identificado a la posición femenina, y un tener, a la masculina, que girarán siempre en torno a un parecer, es decir, a un hacer semblante de hombre y de mujer, ambas posiciones discursivas. ${ }^{11}$ Es preciso señalar, asimismo, que la irrealización de la complementariedad entre ambas posiciones, se exhibe también en relación al falo: visto desde la posición femenina, es el hombre quien tiene el falo y, al revés, la primera es el recordatorio de la castración del segundo; el recordatorio de que, en verdad, no lo tiene. Sin embargo, es el falo en tanto significante el que ordena el juego entre semblantes de hombre y de mujer, permitiendo que una parte del goce sexual se sostenga en el orden del discurso. En este sentido, el semblante es aquello que habilita un hacer con eso que no se tiene, un hacer por y a pesar del núcleo traumático que supone la asunción de una posición sexuada. Por supuesto que no lo hará sin tropezar, en la medida en que el goce, siempre singular, es precisamente aquello que "no sirve para nada" (Lacan, 1991:11), es decir, ese punto de repetición que siempre se

${ }^{11}$ Más allá de las relecturas críticas que puedan establecerse sobre del abordaje lacaniano de la diferencia sexual como binaria -aunque no identificada con una dimensión biológica o anatómica-, lo que nos interesa remarcar es que toda posición sexuada estaría signada por el semblante. En este sentido, es relevante enfatizar que a partir de las fórmulas de la sexuación, las posiciones masculinas o femeninas son lugares que se alcanzan, es decir, que se deviene -no se es- hombre o mujer. El punto estaría en interrogar acerca de la multiplicidad de modos de estar en el semblante y la posibilidad de su ampliación, independientemente de lo biológico o anatómico. 
figura como plus, que produce malestar y cuya in aprehensibilidad no cesa nunca de no-escribirse.

\section{IV}

Cuando al principio del trabajo indicábamos la triple articulación del nudo borromeo lo hacíamos precisamente para pensar los distintos modos en que los anudamientos se constituyen, bajo qué especificidades, qué administraciones y qué órdenes. Es en este sentido que nos interesa pensar en qué medida se da en la contemporaneidad, a partir de ciertos discursos, una conjugación entre lo imaginario y lo real -a través de amarres simbólicos- o, más aún, la puesta en escena de una imagen que pretende acceder a lo real o suplantarlo enteramente.

Si el semblante es el modo siempre enmascarado del mostrarse, el simulacro implica el borramiento de lo imitativo, de la mímica o de la parodia, es decir, el borramiento de la referencia. No se trata de una figuración de la realidad que, contra todo impedimento, se muestre cerrada o saturada. Ese, podríamos sostener, es el modo necesario en que operan las representaciones fantasmagóricas, ya que estas solo pueden funcionar sosteniendo la posibilidad de la universalidad, la creencia y la fe en que ese es el modo de simbolizar, y no meramente uno más entre otros.

Ello no ocurre con el simulacro. Esta es una forma de la figuración que no es tal, movida por la aspiración de exhibir lo real encarnado; es la sobrerrepresentación que termina por menoscabar los fundamentos de la representación misma, arribando a una duplicación de lo real, bajo la espera de su mostración más clara, más pura, sin distorsión. Esa es la tesis de Jean Baudrillard en Cultura y simulacro [1977], donde advierte que la realidad solo se muestra en la posmodernidad bajo la forma de la hiperrealidad, a partir de "una suplantación de lo real por los signos de lo real, es decir, 
de una operación de disuasión de todo proceso real por su doble operativo, máquina de índole reproductiva, programática, impecable, que ofrece todos los signos de lo real y, en cortocircuito, todas sus peripecias" (1987: 7). El autor realiza un diagnóstico de época en relación la primacía de la simulación que exalta el detalle más microscópico -e insignificante a la vez-y seńala que, sin embargo, ello no ha implicado una ganancia de perspectiva o de profundidad respecto de la realidad, sino más bien, al revés. En un exceso de transparencia, el simulacro evidencia una mostración hiperdefinida de la realidad que porta una "fasinación intrínseca eternamente deslumbradora" (1987: 12) y que privilegia lo visual por sobre otros sentidos. Al mismo tiempo, la simulación imposibilita la emergencia de la representación, de la mirada, de un modelo o de la referencia: "al contrario que la utopía, la simulación parte del principio de equivalencia, de la negación radical del signo como valor, parte del signo como reversión y eliminación de toda referencia" (1987: 13). Aquellos discursos de inspiración cientificista que imperan en la actualidad se muestran desembarazados de metáforas, bajo la ostentación de una objetividad que parecería no caer en el engańo del semblante. Sin embargo, y como señala Miller (2009) siguiendo a Lacan, los desengañados, aquellos que suponen que pueden prescindir de los semblantes por haberse topado con su carácter metafórico, yerran de todas formas ya que, por más desengañados que estén, lo real sigue allí. ${ }^{12}$

12 "Destaquemos lo que implica el título de Lacan 'Les non-dupes errent' ['Los desengañados se engañan o los nombres del padre’]. ¿Quiénes son los desengañados? ¿De qué están desengañados? Están desengañados de los semblantes; por conocerlos como tales, creen poder prescindir de ellos. Sin embargo, no utilizar los semblantes es estar engañado de otra manera. Por otra parte, y debido justamente a su desengaño, el desengañado yerra, si me permiten, no está en su lugar real, no vuelve al mismo sitio" (Miller, 2009: 15). 
Por supuesto, y como intentamos desarrollar más arriba, la dimensión de representación simbólica e imaginaria no se puede erradicar de la experiencia de los seres hablantes; no podemos prescindir de ella incluso cuando esté más desprestigiada o devaluada. Las referencias simbólicas funcionan y ordenan la vida en común. El paradigma del simulacro que instaura la idea de la pura imagen como modo privilegiado del decir supone una imaginarización de lo real, en detrimento de la metaforización -de investidura imaginaria- que tiene efectos múltiples y de gran envergadura.

Hay dos interrogantes que podrían plantearse en este sentido. En primer lugar, si acaso esta simulación de una hiperrealidad que entiende a lo real "como aquello de lo cual es posible dar una reproducción equivalente" (Bermúdez et. al., 2018), no termina por ser un movimiento de obturación de la imposibilidad, de taponamiento de aquello que la metáfora no puede subsumir en el semblante, ${ }^{13}$ a modo de respuesta ante el aparente desengańo acerca de la "irrealidad" de lo simbólico. Por otra parte, si la creciente aspiración por lo puro, natural, objetivo y limpio de toda falsedad no tiene efectos sobre los lazos sociales. En efecto, si el semblante tiene una valía, es precisamente porque nos brinda algunas coordenadas para vincularnos con el Otro, porque sienta las bases para un lazo social que no esté exclusivamente signado por la agresividad especular, por una visión del otro como amenaza, sino más bien como sustento necesario para ser en el mundo.

${ }^{13}$ Algunos trabajos recientes (Córdoba et. al., 2017; Bermúdez et. al., 2018) encuentran en la proliferación de identidades sexuales un intento -del orden del simulacro- por rectificar y nombrar el goce sexual, en detrimento de la posición sexuada como semblante, buscando "ajustar la anatomía a lo que se considera una particularidad de goce” (Bermúdez et. al., 2018: 115). Si bien no es el objeto de indagación de este escrito, es posible interrogarse en este sentido acerca del modo en que la lógica del capital se nutre de la multiplicidad de identidades sexuales como si de mercancías se tratase. 
Sin dudas, hay un agujero en toda operación simbólica e imaginaria que se verifica, también, en el orden del semblante. Esto significa que, por más que el sujeto sea un efecto del discurso, siempre será un efecto real por cuanto nunca queda completamente "atrapado" en él. Hay un resto mortificante introducido por la representación, que a lo largo de la enseñanza de Lacan tomará distintos nombres -entre otros, goce, objeto $a$, sinthome-, un imposible no aprehensible en el orden del sentido. Por eso mismo, el simulacro es el opuesto del semblante, es aquello que pretende pronunciarse sobre lo real o, más aún, presentarse como lo real mismo, suponiendo prescindir de lo metafórico y, por lo tanto, de su anudamiento a lo simbólico. Creer que una imagen puede mostrar, decir, imaginar lo real no solo constituye un imposible, sino que además tiene efectos visibles cuando esa -supuesta- pura imagen muestra su reverso, un cuerpo que no es tal como fue imaginado; un real devastador; una realidad despedazada.

Sin establecerse aquí una crítica u oposición a lo imaginario -que por cierto, como intentamos exponer, es fundamental e imprescindible por ser expresión misma de la experiencia-, repensar y recuperar la categoría de semblante en tanto conjugación de los tres registros, atendiendo a sus bordes, sus imposibles y agujeros, quizás pueda habilitar otras lecturas sobre los modos de subjetivación política y social más allá de las encerronas hiperindividualizadas e individualizantes que circulan en detrimento de la inscripción discursiva. 


\section{Bibliografía}

Bassols, Miquel, 2017, "El cuerpo, lo visible y lo invisible", en Luis Tudanca, Paula Gil, Ruth Gorenberg, Graciela Rodriguez de Milano (comps.) Lo imaginario en Lacan, Grama, Buenos Aires.

Baudrillard, Jean, 1978, Cultura y Simulacro, Kairós, Barcelona.

Butler, Judith, 2007, El género en disputa. El feminismo y la subversión de la identidad, Paidós, Barcelona.

Charaf, Darío, 2019, Ética de lo imposible, Modesto Rimba, Buenos Aires.

Baudes de Moresco, Mercedes, 2011, Real, Simbólico, Imaginario: Una introducción, Letra Viva, Buenos Aires.

Bermúdez, Silvia, Casali, et. al., 2018, “Todos trans”, en X Congreso Internacional de Investigación y Práctica Profesional en Psicología XXV Jornadas de Investigación XIV Encuentro de Investigadores en Psicología del MERCOSUR,. Facultad de Psicología, Universidad de Buenos Aires, Buenos Aires.

Castoriadis, Cornelius, 1993, La institución imaginaria de la sociedad, Tusquets, Buenos Aires.

Copjec, Joan, 2006, El sexo y la eutanasia de la razón. Ensayos sobre el amor y la diferencia, Paidós Ibérica, Barcelona.

Córdoba, María de Los Angeles, et. al., 2017, "La clínica psicoanalítica hoy, las sexualidades contemporáneas. Cross dressing y transexualidad", en IX Congreso Internacional de Investigación y Práctica Profesional en Psicología XXIV Jornadas de Investigación XIII Encuentro de Investigadores en Psicología del MERCOSUR, Facultad de Psicología, Universidad de Buenos Aires, Buenos Aires.

Farrán, Roque, 2009, "Lógica del nudo borromeo: Un paradigma del corte estructural. Notas para una filosofía psicoanalítica", 
Nómadas. Revista Crítica de Ciencias Sociales y Jurídicas, núm. 22, pp. 67-80.

Mankoff, Sonia, 2018, "Sujetos vigilados y vigilantes en la sociedad de control", Lapso. Revista anual de la Maestría en Teoría Psicoanalítica Lacaniana, núm. 3, pp. 19-23.

Marchart, Oliver, 2009, El pensamiento politico postfundacional. La diferencia politica en Nancy, Lefort, Badiou y Laclau, Fondo de Cultura Económica, Buenos Aires.

Laclau, Ernesto y Mouffe, Chantal, 2006, Hegemonía y estrategia socialista. Hacia una radicalización de la democracia, Fondo de Cultura Económica, Buenos Aires.

Lacan, Jacques, 1972, "Conferencia en Milán del 12 de Mayo de 1972”, Olga Mabel Máter (trad.), versión inédita.

, 1991, El seminario de Jacques Lacan, Libro XX, Aún (19721971), Paidós, Buenos Aires.

, 2003a, "El estadio del espejo como formador de la función del yo [je] tal como se nos revela en la experiencia psicoanalítica", en Escritos I, Siglo xxi, Buenos Aires.

, 2003b, "La significación del falo", en Escritos II, Siglo XXI, Buenos Aires.

,2003c, "Subversión del sujeto y dialéctica del deseo en el inconsciente freudiano", en Escritos II, Siglo XXI, Buenos Aires. , 2008, El seminario de Jacques Lacan, Libro XVI, De un Otro al otro (1968-1969), Paidós, Buenos Aires.

, 2009, El Seminario, Libro IX, La identificación, Buenos Aires, versión inédita.

, 2011, El seminario de Jacques Lacan, Libro XVIII, De un discurso que no fuera del semblante (1971), Paidós, Buenos Aires.

, 2012 El seminario de Jacques Lacan, Libro XIX, O peor (1971-1972), Paidós, Buenos Aires. 
Laurent, Eric, 2016, El reverso de la biopolitica, Grama, Buenos Aires.

Leserre, Lucas, 2018, "Una selfie para serfeliz", en Inés Sotelo y Lucas Leserre (comps.), Psicoanálisis orientación lacaniana: recorrido del goce en la enseñanza de Jacques Lacan, JCE Ediciones, Buenos Aires.

Merleau-Ponty, Maurice, 2010, Lo visible y lo invisible, Nueva Visión, Buenos Aires.

Miller, Jacques-Alain, 2004, La experiencia de lo real en la cura psicoanalitica, Paidós, Buenos Aires.

, 2009, De la naturaleza de los semblantes, Paidós, Buenos Aires.

,2010, Extimidad, Paidós, Buenos Aires.

, 2014, El ultimísimo Lacan, Paidós, Buenos Aires.

Sartre, Jean Paul, 2005, Lo imaginario, Losada, Buenos Aires. , 2006, La imaginación, Edhasa, Barcelona.

Milner, Jean-Claude, 1999, Los nombres indistintos, Editorial Manantial, Buenos Aires.

Thompson, Santiago (2014). "La categoría lacaniana de semblante", en VI Congreso Internacional de Investigación y Práctica Profesional en Psicología XXI Jornadas de Investigación Décimo Encuentro de Investigadores en Psicología del MERCOSUR. Facultad de Psicología, Universidad de Buenos Aires, Buenos Aires.

Žižek, Slavoj, 2003, El sublime objeto de la ideología, Siglo XxI, Buenos Aires.

Zupančič, Alenka, 2013, "Diferencia sexual y ontología”, en Ana Cecilia González y Begonya Saez Tajafuerce (eds.), Ser-para-elsexo. Diálogos entre filosofía y psicoanálisis, Ediciones S\&P, Barcelona. 